\title{
COOPERAÇÃO PARA A INOVAÇÃO: PERFIL DA INDÚSTRIA BRASILEIRA NO DESENVOLVIMENTO EM P\&D ${ }^{1}$
}

\author{
Rafaela Carnevale \\ Doutoranda em Economia - Universidade Federal de Uberlândia \\ E-mail: rafaelacarnevale@hotmail.com \\ Ana Paula Macedo de Avellar \\ Instituto de Economia - Universidade Federal de Uberlândia \\ Pesquisadora CNPq e FAPEMIG \\ E-mail: anaavellar@ufu.br \\ Marisa dos Reis Azevedo Botelho \\ Instituto de Economia - Universidade Federal de Uberlândia \\ E-mail: botelhomr@ufu.br
}

\begin{abstract}
RESUMO: O objetivo deste artigo é descrever o perfil das empresas que adotam a cooperação para a inovação como forma de desenvolver atividades de $\mathrm{P} \& \mathrm{D}$ no Brasil no período recente. A metodologia adotada foi uma análise descritiva das empresas que cooperam para inovar, segundo seus parceiros de cooperação, objetos de cooperação, tamanho, entre outras características, utilizando-se de dados da PINTEC 2008 e 2011. Os resultados encontrados apontam que a cooperação para a inovação tem ganhado importância para um maior número de empresas brasileiras, sobretudo, entre as de menor porte, na medida que possibilita maior qualificação da mão de obra, elemento este, chave para o desenvolvimento das inovações, acompanhado do desenvolvimento em P\&D, uma vez que verifica-se uma elevação dos gastos para estas atividades.
\end{abstract}

Palavras-chave: Cooperação; Inovação; PINTEC.

ABSTRACT: The purpose of this paper is to describe the profile of firm that adopt cooperation to developed R \& D activities in Brazil. The methodology adopted was a descriptive analysis of the firms that cooperate to innovate, considering the importance of partners, objects of cooperation, size, using data from PINTEC 2008 and 2011. The results indicate that cooperation in innovation activities has obtained more importance for a greater number of Brazilian firms, especially among the small size, as it allows greater qualification of the workforce, a key element for the development of innovations, accompanied by the development in R \& D..

Key words: Cooperation; Innovation; PINTEC.

Área Temática: 4.4 Redes de inovação - alianças de P\&D, interações universidade-empresa, cadeias

\section{Classificação JEL: O30}

\footnotetext{
${ }^{1}$ As autoras agradecem o apoio do CNPq e FAPEMIG.
} 


\section{INTRODUÇÃO}

O objetivo deste artigo é verificar o perfil das empresas que adotam a cooperação para a inovação como forma de desenvolver atividades de $\mathrm{P} \& \mathrm{D}$ no Brasil no período recente.

A cooperação para inovação vem sendo considerada uma alternativa interessante para a empresa ampliar seu desempenho inovativo no mercado. Desde a década de 80 tem ampliado o número de atividades de cooperação entre empresas e instituições, como por exemplo, outras empresas, universidades, institutos de pesquisas, entre outros.

A interação universidade-empresa (IUE) é um mecanismo que possibilita à empresa o acesso aos conhecimentos científicos e tecnológicos desenvolvidos na atividade acadêmica, bem como a outros resultados da pesquisa acadêmica. Entretanto, os resultados dos esforços da IUE dependem de fatores distintos, como a capacidade da empresa em absorver o conhecimento externo. Empresas com maiores CAs tendem a buscar conhecimento externo e melhor usufruir da interação desde o início do processo.

O desenvolvimento dessas capacidades pode ser favorecido pela qualificação da mão de obra e por atividades internas de P\&D. A cooperação é um meio útil de explorar tecnologias e conhecimentos externos. Ela permite que as empresas obtenham ativos complementares e compartilhem custos e riscos. Principalmente para as empresas em fase de arranque cujos recursos tendem a ser limitados, a cooperação para inovação via P\&D parece mais eficaz (OKAMURO, KATO e HONJO, 2011).

Neste sentido, esta pesquisa possui como hipótese a ideia de que a cooperação para a inovação tem ganhado importância para um maior número de empresas brasileiras, na medida que possibilita maior qualificação da mão de obra, acompanhado do desenvolvimento em $\mathrm{P} \& \mathrm{D}$.

\section{COOPERAÇÃO PARA INOVAÇÃO COMO ELEMENTO FUNDAMENTAL DO DESENVOLVIMENTO DE P\&D}

Esta seção abordará duas temáticas sobre o tema (i) a cooperação para inovação o desenvolvimento de P\&D: seu significado e importância, (ii) as experiências evidenciadas pela literatura no cenário internacional da relação ciência, indústria e atividades inovativas.

\subsection{COOPERAÇÃO PARA INOVAÇÃO O DESENVOLVIMENTO DE P\&D: SEU} SIGNIFICADO E IMPORTÂNCIA E ALGUMAS PESQUISAS EMPÍRICAS SOBRE O TEMA

A inovação bem-sucedida depende do desenvolvimento e da integração de novos processos de inovação. Parte deste conhecimento chegar à empresa a partir de fontes externas, sendo que vários autores têm documentado sua importância para as decisões da empresa, e seu impacto no crescimento econômico. Um desafio enfrentado por esta literatura tem sido a medição desses fluxos de informação ou "spillovers" entre empresas (CASSIMAN e VEUGELERS, 2002).

Estes mesmo autores defendem que há uma relação significativa entre os fluxos de informação externos e a decisão de cooperar em P\&D. Empresas que classificam fontes de informação geralmente disponíveis como elementos mais importantes para a sua inovação (spillovers de entrada) são mais envolvidas ativamente, ao mesmo tempo, estas empresas são mais eficazes na apropriação dos resultados de sua inovação (CASSIMAN e VEUGELERS, 2006).

$\mathrm{O}$ fato de as empresas realizarem aquisições internas e externas de conhecimento simultaneamente sugere que estas atividades são complementares, isto é, o retorno marginal para uma atividade aumenta à medida que a intensidade das outras aumenta. $\mathrm{O}$ seu próprio know-how interno, apresenta retorno marginal às estratégias externas de aquisição de conhecimento. Isto é uma reminiscência da noção de "Capacidade de absorção", introduzida por Cohen e Levinthal (1989), que salienta a importância de estoque de conhecimento prévio para efetivamente escanear, analisar e absorver know-how externo. Ao mesmo tempo, o acesso a know-how externo pode alavancar a eficiência das atividades internas de P\&D, pelo menos, quando a empresa está disposta a aceitar ideias e conhecimentos externos (CASSIMAN e VEUGELERS, 2006). 
A cooperação entre organizações e agentes é capaz de fornecer pistas sobre como criar e melhorar as oportunidades de pesquisa que contribua para a construção de sistemas nacionais de inovação através de empresas em fase de arranque. Muitos estudos existentes argumentam que estas cooperações têm um papel importante em grandes inovações. No entanto, vale destacar que para algumas empresas de sua limitada experiência e recursos empresariais se tornam obstáculos à inovação. Para compensar essas deficiências, alianças com organizações externas, em especial para a cooperação em termos de $\mathrm{P} \& \mathrm{D}$ estão sendo consideradas uma boa estratégia produtiva (OKAMURO, KATO e HONJO, 2011).

A cooperação em $P \& D$ permite às empresas em fase de arranque, partilhar custos e riscos, melhorando assim a produtividade empresarial. O papel da qualificação do capital humano também tem sido discutido na literatura. Segundo, Colombo e Grilli (2005) empresas de base tecnológica estabelecidas por indivíduos com maior capital humano apresentam tem um impacto positivo no seu desempenho. Isso é, capital humano dos fundadores é um recurso valioso e desempenha um papel fundamental para o processo de inovação. Embora o desempenho da empresa reflita a estratégia corporativa, incluindo a decisão de formam uma aliança, o capital humano pode exercer uma influência significativa nos tipos de alianças, incluindo a cooperação em P\&D (OKAMURO, KATO e HONJO, 2011).

A partir da década de 60 , se observa um aumento do número de empresas que utilizam a cooperação. No entanto, nas décadas após os anos 1980 que o maior número de atividades de cooperação pode ser observado, quando ficou claro para as empresas que seus conhecimentos internos não são suficientes para obter uma inserção inovadora no mercado. Desta forma, estas atividades passaram a representar oportunidades de acesso ao conhecimento e recursos para acelerar o processo inovador da empresa (HAGEDOORN, 2002).

A cooperação para inovação entre diferentes instituições para a realização de atividades inovadoras pode ser um recurso importante para uma empresa permanecer em uma posição de liderança no mercado. Entretanto, no Brasil, esta estratégia ainda está em seus estágios iniciais. Sendo que a indústria de transformação, qual representa 50\% das empresas inovadoras (50\%) das quais apenas $15 \%$ cooperam em P \& D (KUPFER e AVELLAR, 2009).

Ao longo de muito tempo algumas pesquisas foram desenvolvidas no âmbito da tentativa de explicar como a temática tem se apresentado na realidade mundial, sendo algumas delas destacadas a seguir.

Cassiman e Veugelers (2002) encontraram resultados que sugerem que a P\&D interno e aquisição de conhecimentos externos são atividades de inovação complementares, mas que o grau de complementaridade é sensível a outros elementos do ambiente estratégico da empresa. Identificaram dependência em P\&D - a importância das universidades e centros de pesquisa como fonte de informação para o processo de inovação - como uma importante complementaridade afetando variável contextual entre interno e atividades de inovação externas.

Okamuro, Kato e Honjo (2011) indicaram que as características específicas do fundador, tais como formação educacional, a saída inovação anterior, e filiação a associações acadêmicas são bastante importantes na determinação da cooperação em $\mathrm{P} \& \mathrm{D}$ com instituições académicas (universidades e institutos de investigação pública). Além do que, forneceram evidências de que saída de inovação prévia dos fundadores e experiência de trabalho têm efeitos positivos e significativos sobre $\mathrm{P} \& \mathrm{D}$. No que diz respeito às características específicas da empresa, foi encontrado que as empresas que investem mais em P\&D tendem a se engajar na cooperação de $\mathrm{P} \& \mathrm{D}$, independentemente do tipo de parceiros. Por fim, verifica-se que as empresas independentes são menos propensas a cooperar em P\&D com institutos acadêmicos, do que subsidiárias e empresas afiliadas.

Nelson e Rosenberg (1993) apontam o entrelaçamento entre essas duas dimensões, destacando-o como uma das características principais dos sistemas de inovação. a ciência tanto "lidera como segue" o progresso tecnológico.

Rosenberg (1982) discute "quão exógena é a ciência". Para ele, os fatores econômicos determinam, até certo ponto, o progresso da ciência, explicitando como o progresso tecnológico 
antecede e estimula o progresso científico. A tecnologia é um "enorme depósito de conhecimento empírico para ser investigado e avaliado pelos cientistas".

Klevorick et al. (1995) investigam no sentido oposto esta mesma relação, ao apresentar evidências empíricas sobre o papel das universidades e da ciência como fonte de oportunidades tecnológicas para a inovação industrial. Especialmente em áreas de alta tecnologia, identificam-se fluxos de conhecimento intensos correndo da infra-estrutura científica para os setores industriais.

Narin et al. (1997) encontram evidências empíricas do vínculo crescente entre a ciência (fundamentalmente financiada pelo setor público) e a capacidade inovativa da indústria dos Estados Unidos.

Desta forma, esses estudos demonstram a relevância das duas dimensões da atividade inovativa, identificando a interação e os feedbacks mútuos entre a ciência e a produção tecnológica nos países desenvolvidos. Assim, o presente artigo justifica-se como maneira de identificar o atual cenário brasileiro desta interação.

\section{PROCEDIMENTOS METODOLÓGICOS}

Para atingir o objetivo deste artigo a pesquisa se baseará no método descritivo das empresas que cooperam para inovar, segundo base de dados, conforme solicitação de tabulação especial das edições de 2008 e 2011 da Pesquisa de Inovação (PINTEC, 2016), realizada pelo Instituto Brasileiro de Geografia e Estatísticas (IBGE).

O universo a ser pesquisado é composto pelo total de empresas que inovaram no período, sendo ele igual a 41.262 em 2008 e 45.950 em 2011. Deste total de empresas, a maior parte são pertencentes à indústria de transformação em ambos os anos, mais precisamente no setor de confecções de vestuários e acessórios.

A amostra foi formada a partir destas empresas inovadoras, porém, qual o processo inovativo se deu por meio da cooperação, assim, chegou-se a um total de 4.285 em 2008 e 7.694 em 2011 empresas que cooperaram para a inovação.

Após a formação da amostra analisada as empresas estão divididas em grupos conforme seus parceiros de cooperação da seguinte maneira:

i. $\quad$ Grupo 1: empresas que cooperam para inovar, independente do parceiro;

ii. Grupo 2: empresas que cooperam com clientes e consumidores;

iii. $\quad$ Grupo 3: empresas que cooperam com fornecedores;

iv. Grupo 4: empresas que cooperam com concorrentes;

v. Grupo 5: empresas que cooperam com outra empresa do grupo;

vi. $\quad$ Grupo 6: empresas que cooperam com empresas de consultoria;

vii. Grupo 7: empresas que cooperam com universidades ou institutos de pesquisa;

viii. Grupo 8: empresas que cooperam com centros de capacitação profissional e assistência técnica;

ix. Grupo 9: empresas que cooperam com institutos de testes, ensaios e certificações;

Após a divisão por tipo de parceiro de cooperação será traçado um perfil, evolutivo entre os anos de 2008 e 2011, das empresas que cooperaram para inovar a partir das características como região de localização, quantidade de pessoal ocupado, qualificação de mão de obra, gastos em atividades inovativas e resultados da inovação.

\section{RESULTADOS E DISCUSSÕES}

No Brasil, do total de empresas pertencentes a indústria nacional, no primeiro período analisado, ou seja, entre 2006 e 2008, 41.262 delas implantaram algum tipo de inovação, sendo que este valor passa a 49.950 no segundo período, de 2009 a 2011. Além disso, ainda do total de empresas no primeiro período $89 \%$ do total de empresas inovadoras fizeram alguma parceria cooperativa ao longo do processo produtivo (36.977 empresas), passando a 76\% (38.257 empresas) no segundo período. 
A Tabela 1 apresenta o número de empresas que cooperaram para inovar independente do parceiro (grupo 1), e segundo o tipo de parceiro da cooperação (grupo 2 a 9). Vale destacar que a cooperação pode acontecer com mais de um parceiro ao mesmo tempo, assim, segundo os dados obtidos, todas as empresas cooperam com o grupo 1 e com mais, pelo menos, um dos demais grupos.

Tabela 1 - Número de empresas que cooperaram para inovar nos anos entre 2006 e 2011

\begin{tabular}{cccc}
\hline Grupo & $\mathbf{2 0 0 6 - 2 0 0 8}$ & $\mathbf{2 0 0 9 - 2 0 1 1}$ & $\Delta$ Percentual \\
\hline Grupo 1 & 4.285 & 7.694 & $79 \%$ \\
Grupo 2 & 1.969 & 4.398 & $123 \%$ \\
Grupo 3 & 2.752 & 5.476 & $98 \%$ \\
Grupo 4 & 702 & 1.959 & $179 \%$ \\
Grupo 5 & 601 & 695 & $15 \%$ \\
Grupo 6 & 1.324 & 2.568 & $93 \%$ \\
Grupo 7 & 1.341 & 2.257 & $68 \%$ \\
Grupo 8 & 1.135 & 2.538 & $123 \%$ \\
Grupo 9 & 1.020 & 2.573 & $152 \%$ \\
\hline
\end{tabular}

Fonte: Dados da Pesquisa, a partir da PINTEC (2016)

Conforme observado, em termos absolutos, o grupo que apresenta maior crescimento no número de empresas que cooperam para inovar é, ao longo de todo o período, o de número 1 , ou seja, aquelas empresas que cooperam para inovar, independente do parceiro, apresentando um aumento de 4.285 para 7.694 empresas. O grupo que apresentou menor crescimento no período, tanto em termos absolutos, quanto em termos relativos, foi o do grupo 5, formado pelas empresas que cooperam com outras empresas do grupo, ao crescer apenas 15\% (de 601 para 695 empresas).

Já em termos percentis, o grupo 4 , ou seja, aquele que a cooperação para inovação ocorre com concorrentes, foi o responsável pela maior variação, sendo que entre os dois períodos analisados o grupo apresentou aumento de $179 \%$ (de 702 para 1.959 empresas), isto indica que a visão sobre a concorrência tem se direcionado para o bem comum.

A Tabela 2 apresenta a localização das empresas que cooperam para inovar, segundo as regiões do Brasil. 
Tabela 2 - Localização das empresas que cooperaram para inovar nos anos entre 2006 e 2011

\begin{tabular}{|c|c|c|c|c|c|c|c|c|c|c|}
\hline \multirow[b]{2}{*}{ Grupo } & \multicolumn{5}{|c|}{ 2006-2008 } & \multicolumn{5}{|c|}{ 2009-2011 } \\
\hline & $\begin{array}{c}\text { Centro- } \\
\text { Oeste }\end{array}$ & Nordeste & Norte & Sudeste & Sul & $\begin{array}{l}\text { Centro- } \\
\text { Oeste }\end{array}$ & Nordeste & Norte & Sudeste & Sul \\
\hline $\begin{array}{c}\text { Grupo } \\
1\end{array}$ & 220 & 266 & 127 & 2.434 & 1.238 & 407 & 706 & 458 & 4.038 & 2.085 \\
\hline $\begin{array}{c}\text { Grupo } \\
2\end{array}$ & 54 & 108 & 57 & 1.260 & 491 & 153 & 349 & 238 & 2.309 & 1.348 \\
\hline $\begin{array}{c}\text { Grupo } \\
\mathbf{3}\end{array}$ & 118 & 145 & 91 & 1.524 & 875 & 286 & 646 & 262 & 2.615 & 1.667 \\
\hline $\begin{array}{c}\text { Grupo } \\
4\end{array}$ & 70 & 87 & 8 & 367 & 170 & 132 & 109 & 62 & 1.047 & 609 \\
\hline $\begin{array}{c}\text { Grupo } \\
5\end{array}$ & 48 & 26 & 26 & 411 & 90 & 27 & 51 & 28 & 481 & 108 \\
\hline $\begin{array}{c}\text { Grupo } \\
6\end{array}$ & 91 & 131 & 34 & 798 & 270 & 134 & 97 & 53 & 1.598 & 686 \\
\hline $\begin{array}{c}\text { Grupo } \\
7\end{array}$ & 60 & 140 & 52 & 702 & 387 & 125 & 306 & 264 & 952 & 610 \\
\hline $\begin{array}{c}\text { Grupo } \\
8\end{array}$ & 78 & 107 & 22 & 656 & 273 & 233 & 238 & 265 & 1.121 & 681 \\
\hline $\begin{array}{c}\text { Grupo } \\
9\end{array}$ & 72 & 99 & 30 & 595 & 223 & 128 & 228 & 177 & 1.291 & 749 \\
\hline
\end{tabular}

Fonte: Dados da Pesquisa, a partir da PINTEC (2016)

Conforme observado, as regiões sul e sudeste são as que mais concentram as empresas pertencentes a todos os grupos, em ambos os períodos, com destaque ao grupo 1 na região sudeste, pois apresentou o maior número delas, num total de 2.434 no primeiro período e 4.038 no segundo. Dos grupos analisados os que apresentaram maiores aumento no número de empresas pertencentes a eles foram o grupo 4, aumentando em $665 \%$ (de 8 para 62 empresas), e o grupo 8 em aproximadamente 10 vezes o número inicial (de 22 para 265 empresas), ambos para a região Norte do país.

A região Norte é a que apresenta menor número de empresa que cooperam para inovação, no entanto, vale destacar que o crescimento do número de empresas com este perfil ali instaladas, vem crescente mais rapidamente do que o observado na região Nordeste, principalmente nos grupos 4, 6 , 7, 8 e 9, onde o aumento do número de empresas superou este estado. Isso indica que as empresas que atuam na cooperação como fonte de inovar estão se espalhando para o Oeste brasileiro, tendência que leva a desconcentração, deste tipo de atividade.

Tiveram redução no número de empresas pertencentes a eles os grupos 5 e 6 , nas regiões de Centro-Oeste e Nordeste, respectivamente, sendo que no primeiro caso a redução foi de 48 para 27 empresas (43\%) e no segundo, de 131 para 97 empresas (25\%).

Quanto à localização dos parceiros de cooperação, apenas aquelas que possuem cooperação para inovação com empresas pertencentes ao mesmo grupo, possuem em sua maioria os seus parceiros localizados no exterior. As empresas que cooperam com fornecedores e com institutos de testes, ensaios ou certificações apresentam como localidade de seus parceiros, na maior parte dos grupos o Brasil, mas não o mesmo estado. Já as demais cooperações ocorrem com parceiros regionais.

A Tabela 3 apresenta os setores em as empresas analisadas pertencem e sua evolução ao longo do período. 
Tabela 3 - Agrupamento setorial das empresas que cooperaram para inovar nos anos entre 2006 e 2011

\begin{tabular}{|c|c|c|c|c|c|c|c|}
\hline \multirow[b]{2}{*}{ Grupo } & \multicolumn{3}{|c|}{$2006-2008$} & \multicolumn{4}{|c|}{ 2009-2011 } \\
\hline & $\begin{array}{c}\text { Extrativist } \\
\mathrm{a}\end{array}$ & $\begin{array}{c}\text { De } \\
\text { transformaç } \\
\text { ão }\end{array}$ & $\begin{array}{c}\text { Serviço } \\
\mathrm{s}\end{array}$ & $\begin{array}{c}\text { Extrativist } \\
\mathrm{a}\end{array}$ & $\begin{array}{c}\text { De } \\
\text { transformaç } \\
\text { ão }\end{array}$ & $\begin{array}{c}\text { Eletricidade e } \\
\text { Gás }\end{array}$ & $\begin{array}{c}\text { Serviço } \\
\mathrm{s}\end{array}$ \\
\hline $\begin{array}{c}\text { Grupo } \\
1\end{array}$ & 69 & 3.796 & 419 & 29 & 6.569 & 82 & 1.013 \\
\hline $\begin{array}{c}\text { Grupo } \\
2\end{array}$ & 56 & 1.696 & 217 & 18 & 3.904 & 8 & 468 \\
\hline $\begin{array}{c}\text { Grupo } \\
\mathbf{3}\end{array}$ & 61 & 2.462 & 229 & 20 & 5.031 & 23 & 402 \\
\hline $\begin{array}{c}\text { Grupo } \\
4\end{array}$ & 11 & 590 & 101 & 9 & 1.703 & 14 & 234 \\
\hline $\begin{array}{c}\text { Grupo } \\
5\end{array}$ & 8 & 503 & 90 & 6 & 589 & 31 & 70 \\
\hline $\begin{array}{l}\text { Grupo } \\
6\end{array}$ & 21 & 1.116 & 188 & 8 & 1.913 & 13 & 634 \\
\hline $\begin{array}{c}\text { Grupo } \\
7\end{array}$ & 25 & 1.117 & 200 & 18 & 1.993 & 57 & 189 \\
\hline $\begin{array}{c}\text { Grupo } \\
8\end{array}$ & 16 & 1.013 & 106 & 11 & 2.317 & 12 & 198 \\
\hline $\begin{array}{c}\text { Grupo } \\
9\end{array}$ & 9 & 886 & 126 & 9 & 2.317 & 19 & 227 \\
\hline
\end{tabular}

Fonte: Dados da Pesquisa, a partir da PINTEC (2016)

A indústria de transformação é o setor industrial que detém maior número de empresas que cooperam para inovar, e também a que apresentou maior aumento em termos absolutos entre os período. O destaque foi novamente apresentado pelo grupo 1, já que apresentou o maior número de empresas, 3.796 no primeiro período e 6.569 no segundo, no entanto em termos relativos, o destaque é o grupo 4, pois elevou neste setor, cerca de $188 \%$ o número de empresas ao longo do período.

Ainda sobre o setor de transformação, o grupo que apresentou menor número de empresas pertencentes a ele, foi o grupo 5, sendo que este também foi o grupo que teve o menor aumento relativos entre os período, num total de apenas $17 \%$, ou seja, elevou-se de 503 para 589 empresas.

O setor que apresentou o menor número de empresas é o de extrativismo, em todos os grupos no primeiro período, sendo que no segundo período, este setor também continuou com valores baixos, com exceção do grupo 2, já que nestes anos, o menor número de empresas foi apresentado pelo setor de eletricidade e gás. O setor extrativista foi o que apresentou o menor número de empresas para um dos grupos em ambos os anos, se comparado com os demais setores, de modo que o grupo 5, foi o responsável por este resultado, ou seja, no primeiro período, este grupo apresentou apenas 8 empresas, reduzindo a 6 no segundo. Além disto, a indústria extrativista apresentou redução no número de empresas para quase todos os grupos, com exceção do grupo 9 , que se manteve em ambos os períodos.

Outro setor que apresentou redução no número de empresas que cooperaram para inovar foi a indústria de serviços, porém apenas para os grupos 5 e 7 . No grupo 5, o valor reduziu de 90 a 70 empresas (22\%) e no segundo grupo, 200 para 189 (5\%), no último período. Tirando estes dois casos, os demais grupos apresentaram aumento no número de empresas para este setor, sendo que para o grupo 6 este aumento, foi em termos absolutos, o maior entre todos os grupos e também entre os setores, destacando-se com uma elevação de $237 \%$ (de 188 para 634 empresas). 
A Tabela 4 apresenta o número de empresas em cada grupo, segundo a faixa de número de empregados.

Tabela 4 -Número de empresas que cooperaram para inovar nos anos entre 2006 e 2011, por faixa de pessoal ocupado

\begin{tabular}{ccccccc}
\hline Grupo & $\begin{array}{c}\text { De } 10 \mathrm{a} \\
99\end{array}$ & $\begin{array}{c}\text { De06-2008 } 100 \mathrm{a} \\
499\end{array}$ & $\begin{array}{c}500 \text { ou } \\
\text { mais }\end{array}$ & $\begin{array}{c}\text { De } 10 \mathrm{a} \\
99\end{array}$ & $\begin{array}{c}\text { De } 100 \mathrm{a} \\
499\end{array}$ & 500 ou mais \\
\hline $\begin{array}{c}\text { Grupo } \\
\mathbf{1}\end{array}$ & 3.271 & 549 & 464 & 6.053 & 1.091 & 622 \\
$\begin{array}{c}\text { Grupo } \\
\mathbf{2}\end{array}$ & 1.489 & 222 & 258 & 3.336 & 661 & 401 \\
$\begin{array}{c}\text { Grupo } \\
\mathbf{3}\end{array}$ & 2.089 & 340 & 323 & 4.262 & 755 & 459 \\
$\begin{array}{c}\text { Grupo } \\
\mathbf{4}\end{array}$ & 569 & 67 & 66 & 1.448 & 325 & 186 \\
$\begin{array}{c}\text { Grupo } \\
\mathbf{5}\end{array}$ & 251 & 127 & 224 & 284 & 174 & 237 \\
$\begin{array}{c}\text { Grupo } \\
\mathbf{6}\end{array}$ & 1.031 & 138 & 156 & 1.958 & 353 & 257 \\
$\begin{array}{c}\text { Grupo } \\
\mathbf{7}\end{array}$ & 909 & 199 & 233 & 1.577 & 348 & 332 \\
Grupo & 938 & 86 & 112 & 1.978 & 355 & 206 \\
$\mathbf{8}$ & & 138 & 183 & 1.834 & 434 & 305 \\
$\begin{array}{c}\text { Grupo } \\
\mathbf{9}\end{array}$ & 699 & & & & & \\
\hline
\end{tabular}

Fonte: Dados da Pesquisa, a partir da PINTEC (2016)

As pequenas empresas, ou seja, aquelas que possuem entre 10 e 99 empregados, são as que mais cooperaram para inovar em ambos os períodos. O que ressalta a importância desta estratégia para as pequenas empresas, conforme discutido no arcabouço teórico desta pesquisa. No primeiro período, o grupo 8 foi o que apresentou o maior percentual de empresas que cooperam para inovar, como de pequeno porte, em relação ao total de empresas pertencentes ao grupo, enquanto no último período, este valor foi apresentado pelo grupo 1 , ou seja, no primeiro caso o valor relativo era de $82 \%$ e no segundo $76 \%$.

Dentre as pequenas empresas o grupo que apresentou maior aumento do número de empresas em termos percentis, foi o de número 9, se elevando em 162\% (de 699 para 1.834 empresas), enquanto para as empresas de médio porte, foi o de número 7 , se elevando em $385 \%$ (de 67 para 186 empresas), e para as de grande porte, foi o de número 6, se elevando em $312 \%$ (de 86 para 355 empresas). Já em termos absolutos o maior aumento foi apresentado pelo grupo 1 para as pequenas e médias empresas, passando de 3.271 a $6.053 \mathrm{e} 549$ a 1.091 , respectivamente, e pelo grupo 8 para as grandes empresas, que elevou-se de 138 a 434 empresas. O menor aumento foi apresentado pelo grupo 1 nas de grande porte, tanto em valores absolutos como percentual, já que este grupo elevou apenas em 5\% o número de empresas, num total de 13 para o período

A Tabela 5 traz informação sobre a qualificação dos trabalhadores nas empresas que cooperam para inovar.

Tabela 5 -Número de pessoal ocupado, segundo qualificação nas empresas que cooperaram para inovar nos anos entre 2006 e 2011

\begin{tabular}{ccccccc}
\hline \multirow{2}{*}{ Grupo } & \multicolumn{3}{c}{ 2006-2008 } & & \multicolumn{3}{c}{$\mathbf{2 0 0 9 - 2 0 1 1}$} \\
& Doutores & Mestres & Graduados & Doutores & Mestres & Graduados \\
\hline Grupo & 3.574 & 5.133 & 22.621 & 3.826 & 5.720 & 32.659 \\
\hline
\end{tabular}




\begin{tabular}{|c|c|c|c|c|c|c|}
\hline 1 & & & & & & \\
\hline $\begin{array}{c}\text { Grupo } \\
2\end{array}$ & 1.955 & 2.949 & 15.299 & 3.579 & 4.712 & 23.987 \\
\hline $\begin{array}{c}\text { Grupo } \\
\mathbf{3}\end{array}$ & 999 & 2.572 & 15.442 & 3.376 & 4.479 & 26.649 \\
\hline $\begin{array}{c}\text { Grupo } \\
4\end{array}$ & 1.331 & 1.475 & 3.880 & 2.707 & 2.762 & 12.180 \\
\hline $\begin{array}{c}\text { Grupo } \\
5\end{array}$ & 562 & 1.687 & 9.168 & 803 & 2.097 & 14.797 \\
\hline $\begin{array}{c}\text { Grupo } \\
6\end{array}$ & 362 & 977 & 5.710 & 850 & 2.691 & 14.280 \\
\hline $\begin{array}{c}\text { Grupo } \\
7\end{array}$ & 3.459 & 4.748 & 18.537 & 3.670 & 4.793 & 20.726 \\
\hline $\begin{array}{c}\text { Grupo } \\
8\end{array}$ & 1.449 & 1.874 & 5.863 & 2.824 & 3.435 & 17.314 \\
\hline $\begin{array}{c}\text { Grupo } \\
9\end{array}$ & 898 & 1.598 & 8.750 & 3.195 & 4.080 & 20.506 \\
\hline
\end{tabular}

Fonte: Dados da Pesquisa, a partir da PINTEC (2016)

Em ambos os períodos os trabalhadores graduados são a maioria nas empresas, sendo que este grupo foi o responsável pelo maior aumento em termos absolutos, com um aumento de 11.756 trabalhadores no grupo 9, já em termos percentuais o grupo 4 foi o que apresentou maior aumento cerca de $213 \%$ entre os períodos. Os mestres foram o segundo grupo com o maior número de empregados nas empresas analisadas, sendo que o maior aumento foi apresentado pelo grupo 6 em valores relativos (cerca de $175 \%$ de aumento) e pelo grupo 9 em valores absolutos, uma elevação de 2.482 trabalhadores. Já os doutores foram acrescidos em maior número, em termos relativos no grupo 9, cerca de $255 \%$ e em termos absolutos no grupo 2, ou seja, 2.377 trabalhadores.

As Figuras 1 e 2 apresentam o número de empresas e seus respectivos gastos em P\&D para ambos os períodos.

Figura 1 -Número de empresas e gastos com P\&D, segundo grupo de empresas que cooperaram para inovar nos anos entre 2006 e 2008

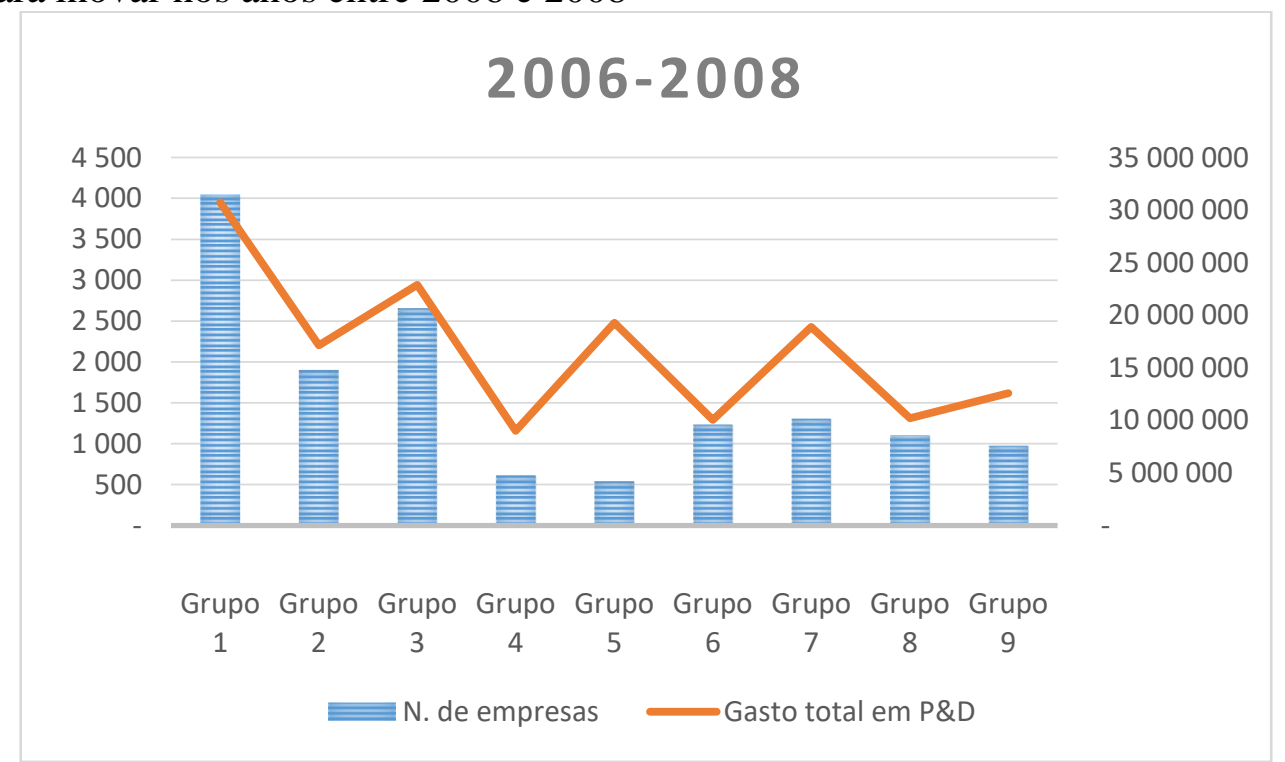

Fonte: Dados da Pesquisa, a partir da PINTEC (2016) 
Figura 2 -Número de empresas e gastos com P\&D, segundo grupo de empresas que cooperaram para inovar nos anos entre 2006 e 2008

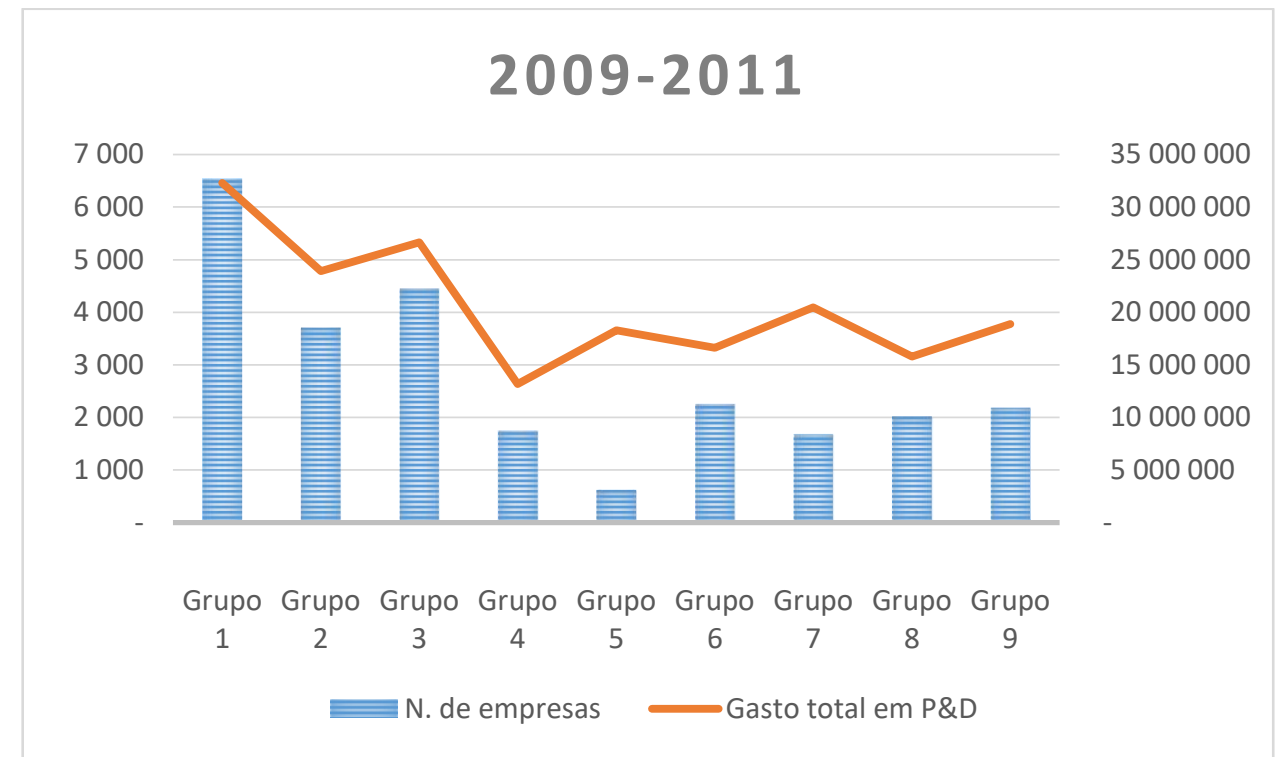

Fonte: Dados da Pesquisa, a partir da PINTEC (2016)

Em geral a maior parte dos grupos tiveram aumento nos gastos destinados às pesquisas de $\mathrm{P} \& \mathrm{D}$, com exceção do grupo 5 que apresentou redução de $5 \%$ do valor gasto nesta atividade. $\mathrm{O}$ maior aumento em termos percentuais foi apresentado pelo grupo 6. Em comparação com os valores gastos destinado ao pagamento de pesquisadores graduados ou pós-graduados, destinados às atividades de $\mathrm{P} \& \mathrm{D}$, todos os grupos tiveram elevação nos gastos, onde também o grupo 6 foi o que teve maior elevação nos gastos. Este fato pode ser explicado pela elevação do número de empregados com mestrado entre os períodos, já apresentados na Tabela 5.

$\mathrm{Na}$ maior parte das cooperações e dos grupos analisados as empresas utilizam-se desta estratégia como forma de fomentar as atividades em $\mathrm{P} \& \mathrm{D}$, se comparados com esta estratégia voltadas ao treinamento de pessoal. As cooperações entre empresas com seus concorrentes e com outras empresas do grupo, foram as únicas em que todos os grupos a maior parte das inovações surgiram via atividades em $\mathrm{P} \& \mathrm{D}$, sendo que o maior número de empresas com esta atividade foi do grupo número 1 no segundo período, num total de 1.571 empresas. Já o grupo a apresentar o menor número de empresas a implementar inovação via $\mathrm{P} \& \mathrm{D}$ foi o de número 5 , com 22 empresas no primeiro período.

Já as cooperações com centros de capacitação profissional e assistência técnica foi a única a apresentar as inovações via treinamento em todos os grupos, nos dois períodos analisados. O destaque deste elemento fica por conta do grupo 1, que implementou quase duas mil inovações via treinamento no segundo período. O menor valor foi apresentado pelo grupo 5, num total de apenas 4 empresas com inovações via treinamento.

A maior parte das inovações implementadas entre as empresas foram de processo, seguido por inovações de produtos e por fim, de ambos. Vale destacar que do grupo geral de empresas que cooperam, independente se por inovação, o número de inovações de produtos reduziu de um período para outro, de modo, que os grupos que cooperaram para inovar apenas tiveram aumento no número das inovações. Apresentou maior aumento das inovações de produtos e de processos o grupo 4, enquanto o grupo 5 foi o que menos elevou suas inovações em ambos fatores.

\section{CONSIDERAÇÕES FINAIS}

O objetivo deste artigo é descrever o perfil das empresas que adotam a cooperação para a inovação como forma de desenvolver atividades de P\&D no Brasil. A metodologia adotada foi uma análise descritiva, a partir da PINTEC 2008 e 2011, das empresas que cooperam para inovar, segundo seus parceiros de cooperação, objetos de cooperação, tamanho, entre outras características para os anos entre 2006 e 2011. 
Os resultados apresentados indicaram um aumento no número de empresas que cooperam para inovar no Brasil, e que este dado se eleva em proporção maior, do que para aquelas empresas que utilizam a cooperação com outro objetivo que não a inovação. Além disso, as empresas que possuem o hábito de cooperar para inovar, o fazem com mais de um parceiro.

A análise das empresas segundo as regiões de localização, apontou que o Sul e Sudeste ainda são as regiões que possuem maior número das empresas com este perfil. No entanto, o Norte é a região que mais apresentou aumento em termos percentuais, e em termos absolutos superou até mesmo o Nordeste, indicando que as empresas que atuam na cooperação como fonte de inovar estão se espalhando para a região Oeste do país, tendência que leva a desconcentração, deste tipo de atividade.

As empresas que mais cooperam para inovar são as de pequeno porte, sendo que as que apresentaram maiores aumentos foram as que cooperam com empresas do próprio grupo, em valores percentuais, e as que cooperam com fornecedores em valores absolutos. Em relação à qualificação, as empresas em todos os grupos, possuem elevado número de trabalhadores com graduação, merecendo destaque para níveis de mestrado e doutorado naquelas empresas que cooperam com universidades ou institutos de pesquisa.

Quanto aos valores destinados aos gastos em atividades de P\&D e pagamento de pesquisadores voltados à essas atividades, as empresas do grupo que cooperam com os clientes e consumidores, são aquelas que tiveram maior aumento em termos absolutos. Por outro lado, em termos percentuais as maiores participações concentram-se nas empresas que cooperam com empresas de consultoria. Apenas as empresas que cooperam com outras empresas do grupo apresentaram redução nos gastos em atividades de $\mathrm{P} \& \mathrm{D}$.

A partir resultados encontrados é possível perceber que apesar do papel relevante das atividades em $\mathrm{P} \& \mathrm{D}$ no processo das atividades inovativas, as inovações via treinamento foram mais recorrentes entre as empresas que cooperam, sendo uma das estratégias que mais tiveram aumento do número de empresas que a adotaram entre um período e outro.

Isto posto não se rejeita a hipótese de que a cooperação para a inovação tem ganhado importância para um maior número de empresas brasileiras, sobretudo entre as de menor porte, na medida que possibilita maior qualificação da mão de obra, elemento este chave para o desenvolvimento das inovações, acompanhado do desenvolvimento em $\mathrm{P} \& \mathrm{D}$, uma vez que os gastos para estas atividades têm se elevado.

\section{REFERÊNCIAS}

CASSIMAN, B.; VEUGELERS, R. (2002). R\&D cooperation and spillovers: some empirical evidence from Belgium. American Economic Review, vol. 92, no. 4 (Sep), pp.1169 - 1184.

CASSIMAN, B.; VEUGELERS, R. (2006). In search of complementarity in innovation strategy: Internal $R \& D$, cooperation in $R \& D$ and external technology acquisition. Management Science, vol. 52, no. 1 (Jan.), pp. $68-82$.

COHEN, W. M., LEVINTHAL, D. A. (1989). Innovation and Learning: The Two Faces of R \& D, The Economic Journal, 99, pp. 569-596.

COLOMBO, M.G., GRILLI, L., 2005. Founders' human capital and the growth of new technologybased firms: a competence based view. Research Policy 34 (6), 795-816.

HAGEDOORN, J., 2002. Inter-firm R\&D Partnership: an overview of major trends and patterns since 1960. Research Policy, 31 (4), pp. 477-492. 
KLEVORICK, A. K.; LEVIN, R. C.; NELSON, R. R. e WINTER, S. G. "On the Sources and Significance of Interindustry Differences in Technological Opportunities." Research Policy, March 1995, 24(2), pp. 185-205.

KUPFER, D.; AVELLAR, A. P. (2009). Innovation and Cooperation: Evidences from the Brazilian Innovation Survey. In: Anais do XXXVII Encontro Nacional de Economia - ANPEC. Salvador.

NARIN, F., NOMA, E., PERRY, R., 1987. Patents as indicators of corporate technological strength. Research Policy 16 (2-4), 143-155.

NELSON R. E ROSENBERG, N., “Technical Innovation and National Systems". In Nelson, R. (ed.). National Innovation Systems: a Comparative Analysis. New York, Oxford: Oxford University, p. 3-21, 1993.

OKAMURO, H; KATO, M.; HONJO, Y. (2011). Determinants of R\&D cooperation in Japanese start-ups. Research Policy, February.

PESQUISA DE INOVAÇÃO (PINTEC). Tabulação especial para 2008 e 2011. 2016.

ROSENBERG, N. Inside the Black Box: Technology and Economics. Cambridge: Cambridge University, 1982. 